\title{
Results of the First Excitation of Helical Coils of the Large Helical Device
}

\author{
S. Imagawa, N. Yanagi, H. Chikaraishi, T. Mito, K. Takahata, S. Hamaguchi, H. Sekiguchi, S. Yamada, \\ T. Satow, Y. Nakamura, S. Satoh and O, Motojima, National Institute for livsion Science, Japan
}

\begin{abstract}
The helical coils of the Large Itelical Device ure large scale pool-cooled superconducting coils. A conductor made of NbTi/Cu compacted strands and a pure aluminum stabilizer was developed to attain high eryostability. The design eurrent of the condector is $13.0 \mathrm{kA}$ at $4.4 \mathrm{~K}$, which produces a tor oidal magnetic field of $3 \mathrm{~T}$ at a major radius of $3.9 \mathrm{~m}$. The first excitation test up to $6.5 \mathrm{kA}$ was conducted successfully in the beginuing of the first conling period. The higher excitations were tried in the second cooling period. The first propagation of a normal zone was observed when resching $1.1 .2 \mathrm{k} \lambda$, and it recovered within 5 s. In the next step, a wide propagation occurred at $11.4 \mathrm{k} \Lambda$, and the quench detection system worked. The coils were designed to satisfy 'coId-end' stability by using the recovery current mensured in short sanaples, but a rormal zone propagates at lower than the lecovery current in the composite conductor stabilized by ver'y low resistive metal.
\end{abstract}

Index Terms--composite conductor, glumuinnm stabilizer, nimimum propagating current

\section{INTRODUCTION}

The Large Helical Dovice (LHD) is a Heliotron-type fission experimental facility for the research of a fusion plasma near a reactor region [1]. In order to demonstrate a steady operation of high perfolmance plasma, the magnet system consists of a pair of superconducting helical coils ( $\mathrm{HCs}$ ) and three pairs of superconducting poloidal coils (PCs). The cxpected toroidal magnetic field is $4 \mathrm{~T}$ at a major radius $R$ of $3.9 \mathrm{~m}$, and the current density of the $\mathrm{HC}$ must be $53 \mathrm{~A} / \mathrm{mm}^{2}$ in order to attain the necessary distance between the plasma and the plasina vacuum vessel. The construction of LHD was determined to be divided into two phases. The $\mathrm{HC}$ is cooled by normal helium in the first plase, and the expected field was set to $3 \mathrm{~T}$, The helinm temperature will be lowered to $1.8 \mathrm{~K}$ in the second phase The PCs were designed to perform with enough cryostability at $4 \mathrm{~T}$ by pressurized nornal helitun cooling.

The construction of the first phase was completed at the end of 1997, and the first cool-down was performed from the middle of February in 1998. In order to establish the reliability of the whole system of LHD, the first excitation of the coils was limited to I.5 T. After 6 weeks' plasma experiment at $1.5 \mathrm{~T}$, the coils were warmed up for upgrade of the plasma heating devices and diagnostics. The second cool-down was performed from the middle of August. Excitation up to the design valuc of $3.0 \mathrm{~T}$ was attempted in October, ancl a wide normal propagation occurred when reaching $11.4 \mathrm{kA}$. The quench detection system acted, and

Shinsaku lnagawn : imngawn $a$ l.HD.nifs ac.jp, Phone : $+81-572-58-2132$, Fax : +81-572-58-2616, 322-6 Oroshi-cho, Toki, Gilu 509-5292, Japan all the coils were discharged by protection resistors. Since the coil protection circuit and the cooling system worked precisely, we contimed the plasma experiments at $1.5 \mathrm{~T}$ and repeated excitation tests. The LHD is now operated at below $2.8 \mathrm{~T}$ at $\mathrm{R}=3.6 \mathrm{~m}$ in the third cooling period. This paper intends to summarize the results of these excitation tests and to clarify the cryostability of the $\mathrm{HC}$.

\section{Design OF HFLICAL COIIS}

\section{A. Design concep}

The HC rotates five times around the plasma vacuum vessel, and three paits of the PCs are arranged to change the vertical and quadrupole magnetic field, while minimizing the stray magnetic field, as shown in Fig. 1. In order to attain high accuracy of coil winding and a high corrent density, a pool-cooled composite conductor of tnedium size was selected for the HC. Since a disturbance by movement of the conductor should be unavoidable in such a latge coil, the HC is expected to satisfy 'cold-end' stability at least.

\section{B. Design of cryostability}

Many types of NbTi superconductors with various internal structures were proposed and examined practically with short sample tests [2]. The final size of the conductor was determined to be $12.5 \mathrm{~mm} \times 18.0 \mathrm{~mm}$ by considering the clyostability, mechanical flexibility for winding and the induced voltage dtring a shut-off. The noninal cutrent is $13.0 \mathrm{kA}$ at $4.4 \mathrm{~K}$ and $17.3 \mathrm{kA}$ at $1.8 \mathrm{~K}$, and the standard operation current at $4.4 \mathrm{~K}$ is $12.5 \mathrm{kA}$ which produces $3.0 \mathrm{~T}$

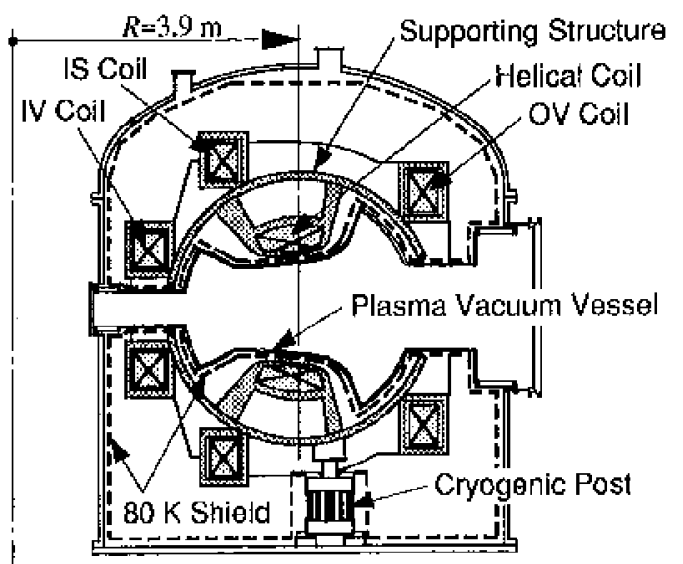

Fig 1, Layout of superconducting coils and surrounding structures of LHD 
of toroidal magnetic field at $R=3.75 \mathrm{~m}$. A pure aluminum stabilizer and a copper sheath were selected to attain a high recovery current and enough strength. Furthermore, the pure aluminum is cladded by $\mathrm{CH}-2 \% \mathrm{Ni}$ to teduce magnetoresistance by Hall currents while maintaining smooth current transfer from the superconducting strands.

The recovery currents of the straight short samples from all the aclual conductors were measured in a bias field of split coils, and the values exceeded the target value, as shown in Fig. 2 [3]. It is the cutrent at which the normal zone disappears in process of decreasing a current after itiducing a certain length of normal zone by a heater. However, the recovery current in a uniform field is estimated to be 15 to $20 \%$ lower than the short samples by analytical study [4]. The wetted surface fraction of conductors of the actual coil was enlarged to 0.692 at the edge region, where transverse fields become the largest but the electromagnetic forces on the insulators are not large. The minimum propagating currents of all the conductors can be estimated by using the typical values of the heat transfer coefficient and magneto-resistance. The lowest value was estimated to be $13.09 \mathrm{kA}$ at $3 \mathrm{~T}$ operation, which means that some regions may not satisfy "cold-end" stability. Still, the HC was considered to be stable, because almost all the conductors satisfy the cryostable condition.

Though the $\mathrm{HC}$ is pool-cooled, the cooling channel is narrow due to the tequirement of laigh curtent density. It is very important to keep a good cooling condition of the conductors. Liquid helium is supplied from the bottom, and the generated gas is taken out from the top. Longitudinal cooling channels inside the coils are arranged at the higher ends of each thyer, as shown in Fig. 3 , and both comers of the top cover of the case. Even the latter area is $300 \mathrm{~mm}^{2}$, but it is not usefitl for the conductor around the bottom. The ends of the first layer are under the most severe condition around the bottom region of the coil, because the field is near its peak and the cooling condition is easy to be deteriorated by accumulation of helium bubbles.

\section{(c) Mechanical design and mamufachuring}

From the aspects of cryostability and mechanical reliability, the conductor motions due to electromagnetic forces must be small. Then, the rigidity of the coil must be high. The HC is expanded in the minor radius direction by the excitation. Tensile stresses of the conductors become the largest in the first layer, and it mainly depends on the compressive modulus of the insulators between conductors. We have developed an insulator with a high compressive modulus, larger than $22 \mathrm{GPa}$, and small thermal contraction. The movement of the first layer was calculated to be $1.1 \mathrm{~mm}$ at $4 \mathrm{~T}$ operation even in the ideal case. Since the fabrication gaps between the conductor and insulator will be collapsed by large electromagnetic forces, the gaps decrease the equivalent rigidity of the coil. The effect was evaluated by assuming that the total gaps are equal to the increase of the displacement of the first layer. The average fabrication gap should be less than $0,065 \mathrm{~mm} /$ layer to keep the stress of the copper sheath under the yield strength of $290 \mathrm{MPa}$. The attained average gap was $0.047 \mathrm{~mm} / \mathrm{layer}$, and the conductor will be operated in the elastic region. Nevertheless, the first layer will move by about $2 \mathrm{~mm}$ due to the excitation.
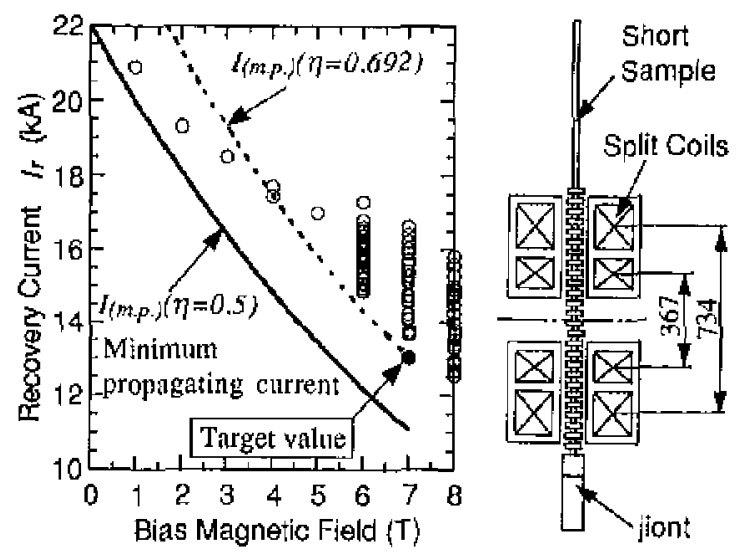

Fig. 2. Measured recovery cuments of short samples and estimated minimum propagating currents. The circles are measured data of short samples at the wetted surface fraction of conductor $\eta=0.5$.

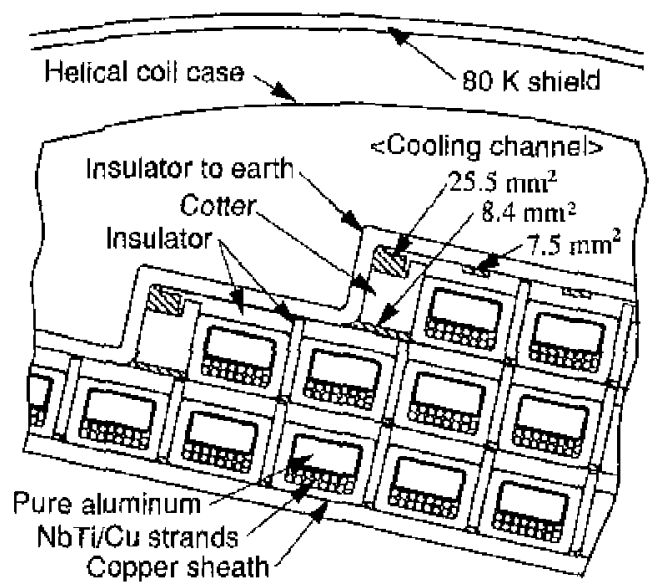

Fig. 3, Cross-section of a lighter coner of 1 st to 3 rd layer of the HC.

\section{Result of small coil test}

In order to study the effect of bias field distribution on recovery currents, we made a coil sample of 10 turns. The inner dianeter is $0.3 \mathrm{~m}$, and the cooling channel is similar to the actual coil. A normal zorje was induced by a heater in the innermost layer. When the current is somewhat ligher than the minimusn propagating current, it propagates to adjacent turns and stops in the lower field. After that, it recovers or stagnates at a certain length. In the latter case, the recovery current is measured by decreasing the trausport current. The obtained data were significantly lower than the expected value, as shown in Fig. 4. The reason may be deterionation of the cooling. Another important result is that the normal zone propagates at a current lower than the recovery current. The reason was revealed to be an excess heat generation by the current diffusing into the pure aluminum stabilizer $[5,6]$. When the propagation stops once by the charige of field or cooling conditions, the current penetrates into the stabilizer in the whole notmal zone, and it begins shrinking. However, it cannot recover after wide propagation, because the cooling conditions become worse by the accumulation of bubbles in the narrow channel between the conductors. 


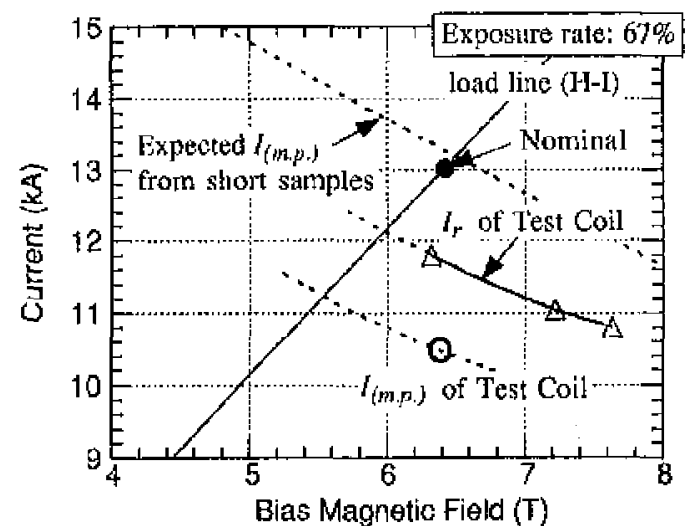

Fig. 4. Recovery current $I r$ and minimum propagating current I(m.p.) of HC Test Coil.

\section{EXCITATION TEST OF THE LHD}

\section{A. Method and results of the expilation tests}

In order to change the current center and to reduce the voltage during a current shut-off, the $\mathrm{HC}$ is divided into three blocks that are called $\mathrm{H}-\mathrm{I}, \mathrm{H}-\mathrm{M}$ and $\mathrm{H}-\mathrm{O}$. Each pair of the blocks is connected to each power supply. Since the mutual coupling factor during the blocks is larger than 0.9 , each current is easy to transfer to the other. The nomal transition of the coil is detected by monitoring the balance voltage that is the difference between the $\mathrm{Hl}$ and $\mathrm{H} 2$ coils

The first excitation tests up to $6.5 \mathrm{kA}$ were carried out stuccessfully within a week in March 1998. After totally 10 weeks' plasma experiments at $1.5 \mathrm{~T}$, excitation up to $3.0 \mathrm{~T}$ was tried in the second cooling period. Excitation up to 2.5 $T$ was attained without any abnomnal signals at a ramp rate of $0.1 \mathrm{~T} / \mathrm{min}$. After twice charging and discharging up to $2.5 \mathrm{~T}$, we tried $2.75 \mathrm{~T}$ by holding the current for $5 \mathrm{~min}$ at $0.1 \mathrm{~T}$ step, as shown in Fig. 5 (a). The first propagation of a normal zone was observed when reaching $2.7 \mathrm{~T}$, and it recovered within $5 \mathrm{~s}$, as shown in Fig. 6 . The outward movement of the conductor induces a positive voltage. The normal propagation also induces a negative voltage due to the inward shift of the current center in addition to the resistive voltage drop. Since the inductive voltage appears in the other blocks by strong mutual conpling, the resistive voltage of the normal zonc is almost separated by subiracting the balance voltage of the neighboring blocks. A large disturbance should have occurted betore the norna propagation, but the signal was masked by the higher voltage itrduced by propagation.

In the next step, a wide propagation occutred at $11.4 \mathrm{kA}$, as slown in Fig. 7. The normal zone expanded more than $15 \mathrm{~mm}$, and shrank gradually. On the way to recovery, it propagated again rapidly and very widely, and the quench detection system worked It was set to act when the balanec voltage higher than $0.2 \mathrm{~V}$ continued more than $3 \mathrm{~s}$. The reason for the second tapid normal propagation is probably deterioration of cooling conditions. Liquid helium would be pushed aside by the generated gas. The estimated resistive losses of the $\mathrm{Hl}-\mathrm{I}, \mathrm{M}$ and $\mathrm{O}$ block were $2.5,1.4$ and 0.92 $M J$, respectively, in addition to the $A C$ losses of $11 \mathrm{MJ}$ in the $\mathrm{HCs}$ and $\mathrm{HC}$ cases. The temperature rises of the case are shown in Fig. 8. It shows that the nortnal propagation occurred near the coil lead of H1-I, that is located at $\# 5$ sector. It also shows that $\mathrm{H}_{2}$ coil kept superconductivity during this quick discharge in spite of the large AC losses.

The quick discharge with a time constant of $20 \mathrm{~s}$, that is called $1 Q$, worked preciscly, and the coils did not suffer any damage. Since $A C$ losses in cluaging by $0.1 \mathrm{~T} / \mathrm{min}$ are larger that the steady heat load, the ramp rate was lowered to 0.01 to $0.02 \mathrm{~T} / \mathrm{min}$ at a field higher than $2.5 \mathrm{~T}$. After repeating excitations, the second excitation up to $2.75 \mathrm{~T}$ was attained at $0.01 \mathrm{~T} / \mathrm{min}$, as shown in Fig. 5 (b), without any abnornal signals. In these excitations listed in Table I and 2, the number and amplitude of the balance voltages decreased in the second and later excitations, and these do not appear in the discharging process from bigh field to near $2.1 \mathrm{~T}$.

After the third cool-down, the excitation tests were conducted by the same pattern. A normal propagation and recover was observed when reaching $2.72 \mathrm{~T}$ of $\# \mathrm{l}-\mathrm{o}$. The number and amplitude of the balance voltages were clearly larger than the last excitation in the previous cooling period. The effect of slow excitation seems to be not large, and the training effects by repeated excitations will be lost partially by warm-up.

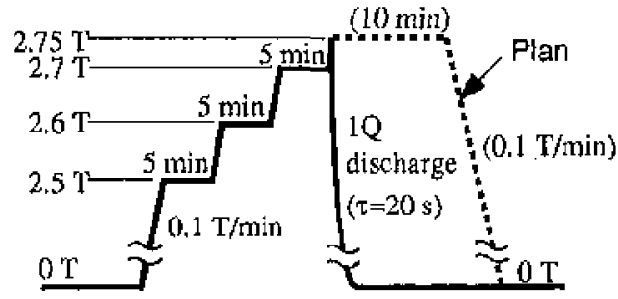

(a) 1 st $\# 1-02.75 \mathrm{~T} @ 3.75 \mathrm{~m}$ on Oetober 21,1998

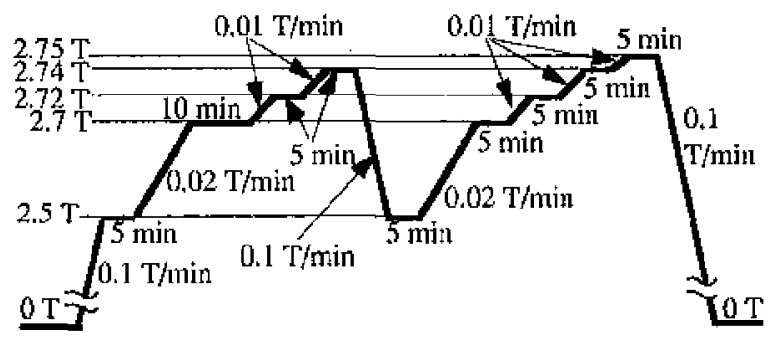

(b) 2nd f $1-02.75 \mathrm{~T} Q 3.75$ nu on December 18,1998

Fig. 5. Excitation pattems of $\# 1-02,75 \mathrm{~T}$

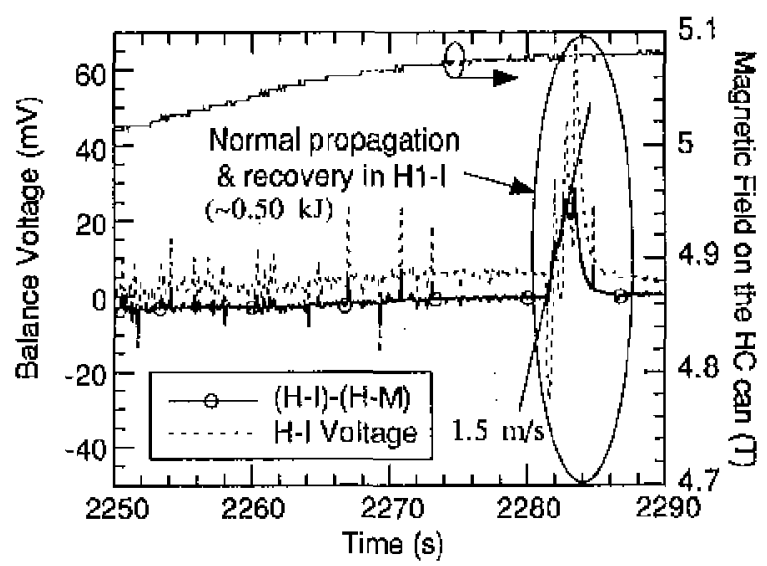

Fig. 6. Voltage of the $\mathrm{HC}$ at the first excitation up to $2.70 \mathrm{~T}$. 


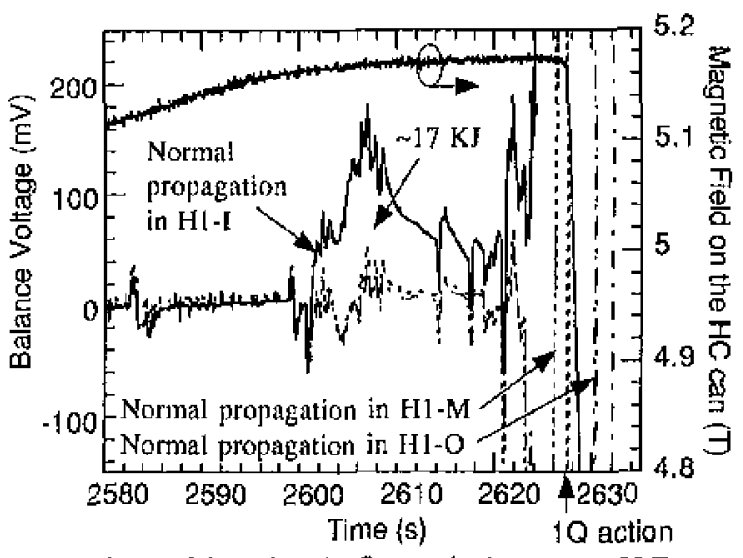

Fig. 7. Voltage of the HC at the first excitation up to $2.75 \mathrm{~T}$.

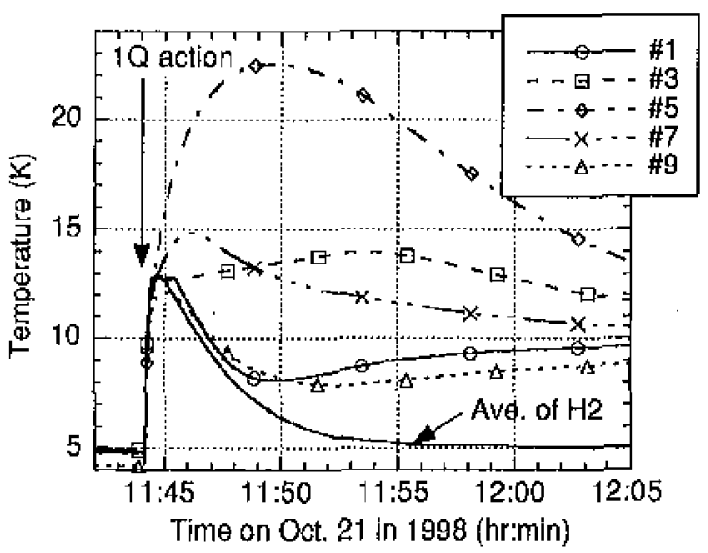

Tig. 8. Temperatures of the IIC case at the outer cguator after $1 \mathrm{Q}$ discharge from $275 \mathrm{~T}$. The deviation of $\mathrm{H} 2$ coil case was less than $1 \mathrm{~K}$.

Table 1 Excitation tosts in the secont cooling period

\begin{tabular}{|c|c|}
\hline Date & Fireld (mode, major radius) \\
\hline $10 / 20$ & $2.5 \mathrm{~T}\left(\# 1-\mathrm{o}_{\mathrm{r}} \mathrm{R}=3.75 \mathrm{~m}\right)(0.1 \mathrm{~T} / \mathrm{min})$ \\
\hline $10 / 21$ & IQ from $2.75 \mathrm{~T}(\# !-0, R=3.75 \mathrm{~m})$ \\
\hline $12 / 1$ & $2.2 \mathrm{~T}(\mathrm{fl} \mathrm{L}-\mathrm{c}, \mathrm{R}=3.75 \mathrm{~m})$ \\
\hline $12 / 3$ & $2.55 \mathrm{~T}(H 1-0, R-3.75 \mathrm{~m})$ \\
\hline $12 / 10$ & $2.7 \mathrm{~T}(\mathrm{HI}-\mathrm{0}, \mathrm{R}=3,75 \mathrm{~m})$ \\
\hline $12 / 16$ & $2.7 \mathrm{~T}(\mathrm{H}]=\mathrm{b}, \mathrm{R}=3.75 \mathrm{~m}), 2.5 \mathrm{~T}(H \mathrm{H}-\mathrm{b}, \mathrm{c}, \mathrm{d}, \mathrm{o})$ \\
\hline $12 / 17$ & $2.74 \mathrm{~T}(\# \mid-\mathrm{o}, \mathrm{R}=3.75 \mathrm{~m}), 2.85 \mathrm{~T}(\not 1-\mathrm{d}, \mathrm{R}=3.6 \mathrm{~m})$ \\
\hline $12 / 18$ & $2.75 \mathrm{~T}(\# 1-0, R=3.75 \mathrm{~m})$ \\
\hline
\end{tabular}

Table 2 Currents of coils for 3 ' $[$ ' at the plasma axis [k $\mathrm{k}]$

\begin{tabular}{llrrr}
\hline mode & IIC & \multicolumn{1}{c}{ OV } & \multicolumn{1}{c}{ IS } & \multicolumn{1}{c}{ IV } \\
\hline \#I-o (standard) & 12.5 & -19.62 & -5.01 & 10.21 \\
\#1-a (wertical elongation) & 12.5 & -21.74 & 5.24 & 5.74 \\
\#I-b (horizontal olongation) & 12.5 & -17.49 & -15.27 & 14.68 \\
\#I-c (outward shift) & 13.0 & -19.60 & -6.80 & 8.09 \\
\#I-d (inward shift) & 12.0 & -10.60 & -3.28 & 12.25 \\
\hline
\end{tabular}

The major radit of the plasma axes are $3.75 \mathrm{~m}$ for $\# 1-0$, a and b, $3.9 \mathrm{mn}$ for $\# 1-0$, and $3.6 \mathrm{~m}$ for $\#]-d$.

\section{B. Abrormal balance volage after normal transition}

We observed the drastic change of the balance voltage in the lirst excitation after the 10 discharge on October $2 \mathrm{~L}$, as show it1 Fig. 9. Since we were afraid of a short circuit in the $\mathrm{HC}$, we checked the change of inductance of the coils and repeated the coil excitations by using small power

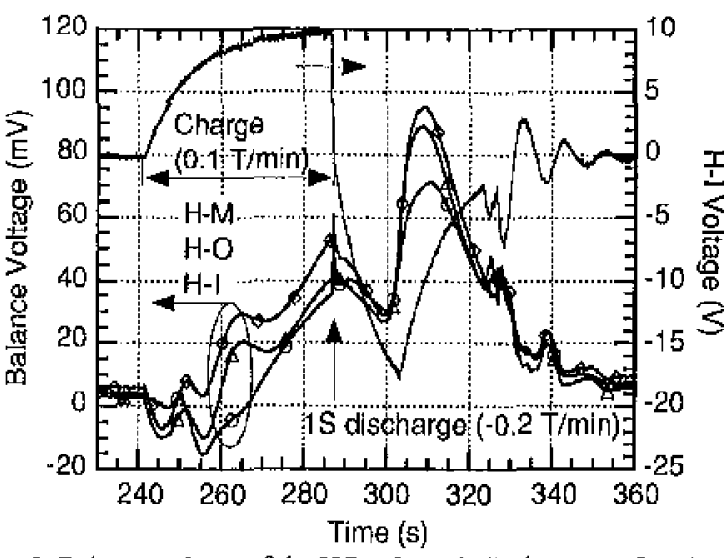

Fig. 9. Balance voltage of the HCs after 10 discharge on Oct. 21 in 1998

supplies, after disassembling of the temperature sensor cables, Since nothing wrong was detected, we tried higher excitations step by step. The abnotmal balance voltage disappeared at an excitation higher than atound $0.8 \mathrm{~T}$. The main reason is considered to be a change of magnetization of the superconducting cables of the $\mathrm{Hl}$ coil that was heated up by the $I Q$ discharge. However, it does not explain the whole phenomenon. $\Lambda$ second circuit or magnetization of other conmponents must be involved.

\section{SUMMARY AND DISCUSSION}

LHD, the world's laugest stellarator, was completed, and excitations were attained up to $2.75 \mathrm{~T}$ which is $88 \%$ of the design value. The $\mathrm{HCs}$ were expected to satisfy "cold-end" stability, but it was revealed that a normal zone propagates at lower than the expected value by excess heat generation during current diffision into a low resistance stabilizer. A kind of training effect was observed in repented excitations. The disturbance seems to be reduced in the second and later excitations, and the disturbance does not occur in the disclarging process from high ficld to $2.1 \mathrm{~T}$. The coils are used safely for plasma experiments by being charged once up to slightly ligher field. Furthermore, a higher excitation is expected by improving the cooling condition or by gating the current of each block.

\section{REFERENCES}

[1] A. Iiyosin, M. Fujiwarn, O. Motojimi, N. Ohynbu and $K$. Yantazaki, "Design study for the Large Helical Device", Fusion Tcelmology 17 (1990) pp. 169-187.

[2] T. Mito, K, Thakahata, N. Yanagi, el al, "Short sample tests of atum inum-stabilized superconductors for Large Helical Device", Fusion Eng. Des. 10 (1993) pp.233-242.

[3] N Yataji, T. Mito, S. Imagawa, K. Takalata, T. Satow, J Yamameto, $O$. Motojinta and The LHD Group, "Dovelapment and quality control of the superconductors for the helieal coils of LHD", Fusion Engineering and Design 41 (1998) gp. 241-246.

[4] S. Jmagawn, S. Masuzaki, N. Yanagi, S. Yamaguchi, T. Satow, J. Yamamoto, O. Motojima and LHD Group, "Design and construetion of helical eoils for I.IID", Fusion Eng. Des. 41 (1998) pp,253-258.

[5] S. Nognchi, A. lshiyama, T. Sntow and N. Yanagi, "Transient stability of large nluminum stnbilized supcreonductors", ASC'98, LIB-11

[G] N. Yanagi, A.V. Givrilin, T, Mito, el al, "Stability characteristics of the aluminum stabilized suporconductor for the LHD hotical coils", Advances in Superconductivity XI (1999) pp.991-994. 